\title{
Perwujudan Keharmonisan Hubungan antara Manusia dengan Alam Dalam Upacara Hindu
}

\section{di Bali}

Ni Made Budiasih ${ }^{1}$

Fakultas Dharma Duta

Institut Hindu Dharma Negeri Denpasar

Abstract

Living things come from food. Food comes from plants. Plants come from rain. Rain comes from YADnya. Yadnya it is karma. Without plants, all living beings cannot carry on their lives, because the basic ingredients of animal and human food are plants. The existence of plants is yadnya from earth and sky to all living things. The teachings of Hinduism include three frameworks, namely tattwa, etika and upacara. In its implementation implemented Hindus in an integrated and intact. But in reality the more prominent part is the ceremonial part. This is because this part is a form of implementation with all its accessories. The big day is Tumpek wariga, also known as bubuh tump, pengatag tump, steering tump. It falls on the day of Saniscara, Kliwon, Wuku Wariga, or 25 days before Galungan. A series of ceremonies and ngatagin ceremonies were held to worship Bhatara Sangkara, the manifestation of Hyang Widhi, invoking the fertility of plants that are useful for human life. Bentuyung), Lord of Plants Plants that are concrete through treating the trees by offering porridge. In addition, Tumpek wariga is also an initial series in preparation for the Galungan holiday. In addition, the Ngerasakin Ceremony is a ceremony that aims to express gratitude to Ida Sang Hyang Widhi Wasa with manifestations as Jero Sedahan Abian and Jero Sedahan Sawah for what has been enjoyed so far from the produce of the earth.

Keywords

Balinese ritual; Yadnya; Hinduism;

\section{PENDAHULUAN}

Tata kehidupan beragama Hindu di Bali mempunyai ciri tersendiri, dibandingkan dengan umat Hindu di
Manca Negara. Pola kehidupan di Bali dilandasi oleh konsep Tri Hita Karana yakni tiga unsur yang menyebabkan kebahagiaan yaitu Tuhan, manusia dan

${ }^{1}$ nimade_budiasih@ihdn.ac.id

WIDYA DUTA | VOL. 14, NO. 1 |2019 
alam. Menjaga kehidupan yang harmonis dengan Tuhan, antara manusia dengan manusia, dan keharmonisan hidup antara manusia dengan lingkungan hidup. Alam merupakan yang takterpisahkan dari suatu ekosistem, yaitu lingkungan sebagai tempat berlangsungnya hubungan timbal balik antara mahluk hidup dan faktor alam, antara mahluk hidup yang satu dan yang lainnya. Lingkungan hidup sebagai media timbal balik mahluk hidup dengan faktor alam yang terdiri dari berbagai macam keadaan dan hubungan yang secara bersama mewujudkan struktur dasar ekosistem sebagai suatu kesatuan yang mantap. Hubungan timbal balik tersebut merupakan mata rantai atau siklus penting yang menentukan daya dukung lingkungan hidup sebagai pembangunan.

Ajaran agama Hindu yang disebut dengan Tri Hita Karana merupakan filsafat hidup umat Hindu dalam membangun sikap hidup yang benar menurut ajaran agama Hindu. Sikap hidup yang benar menurut ajaran Hindu adalah bersikap yang seimbang antara percaya dan bhakti pada Tuhan dengan mengabdi pada sesama manusia dan menyayangi alam berdasarkan Yajna. Yang membutuhkan telaksana ajaran Tri Hita Karana adalah manusia. Manusia secara hakiki adalah identik dengan alam. Manusia adalah bagian dari ekosistem alam juga. Alam semesta disebut sebagai "bhuana agung" (makrokosmos) dan manusia sendiri disebutnya sebagai "bhuana alit" (mikrokosmos). Manusia dalam hidupnya selalu menyatukan diri dengan alam, yang berarti manusia hendaknya mempergunakan alam sebagai paradigma dalam bertindak (Wiana : $2007: 24)$.
Tumpek bubuh / tumpek wariga juga disebut Tumpek Pengatag merupakan turunnya Hyang Ciwa untuk memelihara keharmonisan kehidupan di dunia. Perayaan tumpek wariga ini 25 hari menjelang Hari raya Galungan bertujuan agar pohon / tumbuh tumbuhan yang ada disekeliling kita diharapkan dapat memenuhi kebutuhan umatnya. Seperti tumbuh tumbuhan, daun daunan dan bunga bungaan .

Dalam konsepsi Hindu, saat Tumpek Pengatag dihaturkan persembahan kepada Ida Sang Hyang Widhi Wasa dalam manifestasi sebagai Sangkara, Dewa Penguasa tumbuhtumbuhan yang dikonkretkan melalui mengupacarai pepohonan. Memang, menurut tradisi susastra Bali, yang menyebabkan tumbuh-tumbuhan hidup dan memberikan hasil kepada manusia adalah Hyang Sangkara. Karenanya, ucapan syukur dan penghormatan kepada Hyang Sangkara mesti dilakukan manusia dengan mengasihi segala jenis tumbuh-tumbuhan.

Perayaan hari Tumpek Pengatag mengajarkan pada umat manusia bahwa kita wajib bersyukur atas harmoni yang membantu kita tinggal dalam alam kehidupan kini. Menghormati dan menghargai bumi dan seisinya, khususnya tanaman yang ada, memberi isyarat dan makna mendalam agar manusia mengasihi dan menyayangi alam dan lingkungan yang telah berjasa menopang hidup dan penghidupannya. Pada Tumpek Pengatag, momentum kasih dan sayang kepada alam itu diarahkan kepada tumbuh-tumbuhan. Betapa besarnya peranan tumbuhtumbuhan dalam memberi hidup umat manusia. Hampir seluruh kebutuhan hidup umat manusia bersumber dari 
tumbuh-tumbuhan. Mulai dari pangan, sandang hingga papan.

Karena itu pula, tradisi perayaan Tumpek Pengatag tidaklah keliru jika disepadankan sebagai peringatan Hari Bumi gaya Bali dan kini bisa direaktualisasi sebagai hari untuk menanam pohon. Tumpek Pengatag merupakan momentum untuk memahami dan bersyukur atas segala jasa Ibu Pertiwi kepada umat manusia. Bersahabat dengan alam, tidak merusak lingkungan, belajar dari pengalaman para leluhur / para tetua Bali di masa lalu, yang telah memiliki visi futuristik untuk menjaga agar Bali tak meradang menjadi tanah gersang dan kerontang akibat alam lingkungan yang tak terjaga.

Kesadaran yang tumbuh dalam pengertian makrokosmik, dalam konteks semesta raya, tidak hanya semata Bali. Visi dan misi dari segala tradisi itu bukan semata menjaga kelestarian alam dan lingkungan Bali, tetapi juga kelestarian alam dan lingkungan seluruh dunia. Istimewanya, segala kearifan itu muncul jauh sebelum manusia dimasa kini menggemakan upaya untuk menjaga kelestarian lingkungan. Jauh sebelum dunia menetapkan Hari Bumi, tradisitradisi Bali telah lebih dulu mewadahinya dengan arif. Bahkan jauh sebelum orang menetapkan Desember sebagai bulan menanam pohon.

Perayaan Tumpek Pengatag
sebagai Hari Bumi gaya Bali
menghadirkan ironi tersendiri. Ketut
Wiana menjelaskan bahwa dalam
berbagai bentuk, ritual dan tradisi itu
berhenti pada wujud fisik upacara
semata, dampak keterjagaan terhadap
lingkungan Bali tak tampak secara
signifikan. Kenyataannya, alam Bali tiada
henti tereksploitasi. Situasi terakhir,

dengan adanya rencana untuk menjual pasir di pesisir pantai Tabanan.

Situasi serba paradoks ini sesungguhnya lebih dikarenakan ide perencanaan dan pelaksanaan dalam bentuk yang menyimpang, pemaknaan yang tidak total atau tanggung terhadap ritual-ritual yang ada. Ritual-ritual itu yang sesungguhnya hanya alat, sebatas wadah untuk mengingatkan, tidak diikuti dengan laku nyata, tidak disertai dengan aksi konkret. Karenanya, yang mesti dilakukan saat ini adalah upaya untuk memaknai ritual-ritual itu secara lebih kontekstual dan total sekaligus menyegarkannya dalam tataran laku tradisi. Perlu ada reaktualisasi terhadap kearifan-kearifan tradisi yang dimiliki Bali.

Karenanya, menurut pandangan Ketut Gobyah, salah satu pemuka masyarakat, akan menjadi menawan, bila Tumpek Pengatag tak semata diisi dengan menghaturkan banten pengatag kepada pepohonan, tapi juga diwujudnyatakan dengan menanam pohon serta menghentikan tindakan merusak alam lingkungan. Dengan tindakan nyata, satu orang menanam satu pohon. Dengan begitu, Tumpek Pengatag yang memang dilandasi kesadaran pikir visioner menjadi sebuah perayaan Hari Bumi yang paripurna. Bahkan, manusia Bali bisa lebih berbangga, karena peringatan Hari Buminya dilakonkan secara nyata serta indah menawan karena diselimuti tradisi kultural bermakna kental.

Mari terus menerus menjaga kebersihan dan kelestarian lingkungan kita. Dalam skala kecil, berawal dari lingkungan tempat tinggal kita dahulu. Menanam tumbuh-tumbuhan untuk kelestarian lingkungan, dan dijadikan sarana memuja Tuhan. Dalam skala yang 
lebih besar lagi, mengaktifkan dengan menanami berbagai jenis tanaman pada banyak lahan tidur di Bali. Hasilnya akan bisa dimanfaatkan masyarakat Bali sendiri tanpa harus tergantung dari pasokan luar Bali, khususnya dalam memenuhi berbagai kebutuhan sarana upacara keagamaan.

Hal inilah yang semestinya kita lakukan secara terus menerus, dan berkelanjutan, mengajegkan flora dan fauna Bali, bahkan di seluruh dunia. Secara berkala dalam merayakan hari Tumpek wariga, di samping secara niskala kita melakukan upacara keagamaan. Dengan demikian, dari Tumpek wariga ke Tumpek wariga berikutnya kita dapat menyaksikan berbagai kemajuan dalam pelestarian tumbuh-tumbuhan Bali.

Upacara Ngerasakin memiliki maksud untuk mengucapkan rasa syukur dan terimakasih para petani kehadapan Ida Sang Hyang Widhi Wasa Yang Maha Esa karena hasil kebun mereka berproduksi dengan baik. Ritual ini biasanya dilaksanakan setiap satu tahun sekali atau enam bulan sekali tergantung kemampuan dari masyarakat setempat. Secara umum masyarakat Banyuatis memiliki pedewasaan di dalam melaksanakan upacara, seperti halnya Upacara Ngerasakin . Umat Hindu menyadari bahwa dalam menjalani hidupnya di dunia ini tidak bisa berdiri sendiri (individu) tetapi selalu membutuhkan orang lain sebagai teman untuk mengarungi hidupnya sampai pada tujuannya yang terakhir, maka itu manusia disebut sebagai makhluk sosial (Purnomohadi, 1993:25). Secara umum dipahami bahwa Upacara Ngerasakin merupakan salah satu pemujaan Sang Hyang Sangkara, yaitu manifestasi Tuhan sebagai Dewanya tumbuh-tumbuhan atau sebagai penunggu lahan pertanian atau disebut dengan Jero Sedahan. Melalui Upacara Ngerasakin merupakan bentuk ekspresi masyarakat kehadapan Tuhan Yang Maha Esa sebagai ucapan terima kasih atau rasa bersukur hasil pertanian yang melimpah ruah. Upacara yang dilaksanakan oleh petani di sangat intens karena dalam keyakinan mereka dengan pelaksanaan ritual kehadapan sang pencipta maka mereka merasa selalu dilindungi dan tanaman mereka akan memperoleh hasil yang maksimal.

\section{PEMBAHASAN}

\section{Bentuk Upacara Ngerasakin} Dalam proses

Upacara

Ngerasakin ada beberapa tahap yang dilaksanakan. Sebelum proses intinya maka terlebih dahulu Nunas Tirta Pengelukatan dengan cara Nyonteng atau dengan menggunakan mantram. Dilanjutkan dengan Ngelukat Banten dan Pelinggih Ida Betare termasuk pemimpin upacara dan juga yang melaksanakan upacara dengan tujuan agar bersih atau suci. Setelah semuanya sudah bersih maka selanjutnya Nuur atau mendak atau memanggil Ida Betara agar berkenan hadir dengan cara memohon atau Ngajum agar beliau berkenan kontak dengan manusia melalui manifestasi-Nya sesuai dengan fungsinya, untuk menyaksikan persembahyangan atau sebagai Pesaksi. Dalam prosesi Upacara Ngerasakin disebut dengan Ngaturang Piuning ke pada Ida Sang Hyang Widhi Wasa dalam manifestasinya sebagai Sang Hyang Raditya dan Pertiwi. Banten yang di gunakan adalah banten Canang Raka, banten Ajuman dan banten Daksina misi segehan.

Kedua, Ngadegang (Stiti) yang dimaksud dengan Ngadegang adalah 
mestanakan Beliau, dalam imajinasi seolah-olah beliau telah duduk pada stananya, dan telah siap menyaksikan dan menerima persembahan upacara yang di suguhkan. Dalam proses menstanakan ini banten yang dipakai dapat di bagi menjadi dua yaitu banten untuk di Pelinggih terdiri dari Canang Raka Tipat Kelanan Misi Taluh Abungkul yang merupakan suguhan unruk Dewa Sangkara. Dan yang kedua adalah banten yang utama atau yang disuguhkan kepada Jero Sedahan Abian atau Jero Sedahan Carik yang terdiri dari banten Pengambean Pengulapan, Banten Sorohan Alit dan Banten Guling alasnya memakai kapar yang terdiri dari : Cacahan, Tumpeng Pitu dan Babi Guling yang di hiasi dengan potongan-potongan hati. Dalam proses Upacara Ngerasakin ada proses Ngayabang, dalam proses Ngayabang yang di pakai adalah Sesontengan yang di ikuti dengan Murak atau memotong kepala guling dan memotong keempat kakinya sebagai simbol bahwa persersembahan sudah disuguhkan atau diaturkan. Dalam Sesontengan dikatakan bahwasanya aturan atau persembahan yang disuguhkan katur atau diterima sehingga untuk kedepannya harapannya agar hasil bumi lebih meningkat lagi dan terhindar dari gangguan manusia, binatang dan penyakit.

\section{Ketiga, Ngamantukang (Pralina)} merupakan proses menghaturkan persembahan untuk memohon agar Beliau berkenan untuk kembali ke Kahyangan (ke sumbernya) karena proses upacara sudah selesai. Dalam hal ini menggunakan sarana sarana (simbol) arak, berem, maka dalam melakukan tetabuhan dengan tujuan prelina dalam hal ini yang dituangkan terlebih dahulu adalah araknya kemudian baru beremnya dengan puja Sesontengan.

Dilanjutkan dengan proses Ngeluarang dengan memakai Segehan Panca Warna, perlu diingat bahwasanya dalam proses Ngelarang ini merupakan memberikan suguhan kepada Bhuta Kala. Bhuta Kala supaya ikut juga menikmati persembahan Guling ini maka telubih, kuping, layah, kuku kaki dan ekornya di potong untuk di persembahkan ke pada bhuta kala yang di taruh di segehan dan di ayabang/di manterai atau bisa juga memakai Sesontengan. Dengan tujuan supaya tidak mengganggu atau merusak abian secara niskala. Sehingga apa yang menjadi tujuan dari pelaksanaan Upacara Ngerasakin bisa terwujud, hidup tentram damai dan hasil yang dicapai bisa menjadi maksimal.

Dalam pelaksanaan Upacara Ngerasakin perlu diungkapakan dimana dan kapan upacara itu dilaksanakan. Proses Upacara Ngerasakin di laksanakan di Tagal/Abian atau ladang dan juga di Carik atau Sawah. Di setiap warga yang memiliki ladang/abian maupun carik/sawah selalu memiliki penunggu berupa pelinggih yang disebut dengan Jero Sedahan Abian untuk di Ladang/abian atau Jero Sedahan Carik untuk di Sawah. Jero Sedahan Abian dan Jero Sedahan Sawah merupakan manifestasi Tuhan dengan fungsi menjaga/melindungi atau Ngeraksa Abian dan Carik. Karena tugasnya menjaga dan melindungi abian atau carik yang menjadi sumber penghasilan petani, maka masyrakat wajib melaksanakan Upacara Ngerasakin dengan maksud untuk mengucapkan rasa syukur atau terima kasih kepada Tuhan dalam manifestasi sebagai Jero Sedahan abian maupun carik yang dikenal dengan membayar upeti atau 
disebut dengan Ngaturang Tiga Sana Suku Empat yang menjadi persembahan utamanya adalah Guling Babi.

Upacara Ngerasakin sebaiknya dilaksanakan bertepatan dengan Tumpek wariga yang dilaksanakan dua puluh lima hari menjelang Galungan yang jatuh pada Sabtu Kliwon Wuku Wariga. Berdasarkan hasil wawancara di atas dan hasil observasi bahwa pelaksanaan Upacara Ngerasakin dilaksanakan menjelang hari raya Galungan, untuk padewasaan sesuai dengan hala ayuning dewasa menurut kalender Bali dalam melaksanakan Upacara Ngerasakin menghindari Pasah dalam Tri Waranya dan yang sering disarankan untuk dilaksanakan adalah beteng maupun kajeng.

\section{Analisis fungsi Upacara Ngerasakin}

Upakara sebagai alat kosentrasi pikiran untuk menuju Sang Hyang Widhi atau manifestasinya misalnya saja bagi orang yang sedang membuat banten, maka dengan tidak sengaja dia sudah membayangkan kehadapan siapa yang akan di persembahkan. Demikian juga bagi orang yang sedang melakukan piodalan atau persembahyangan menganggap bahwa Dewa yang dipuja berada pada Daksina Pelinggih atau Tapakan yang telah dibuat. Upakara mempunyai fungsi sebagai alat kosentrasi, persembahan/korban suci, sarana pendidikan menuju Ida Sang Hyang Widhi Wasa, sarana penyucian, sarana perwujudan menuju Ida Sang Hyang Widhi Wasa dalam berbagai manifestasi dan sarana meningkatkan estetika (Arwati 1992 :2). Berkenaan dengan diatas bahwa Upacara Ngerasaki merupakan fungsi pelayanan terhadap Ida Sang Hyang Widhi Wasa atau Tuhan Yang Maha Esa, dapat dilihat dari proses pembuatan dan menyiapkan sarana prasarana upakara yang di gunakan dalam pelaksanaan uapacara. Seperti halnya dalam proses pembuatan Babi Guling, banten daksina, Canang Raka, Ajuman, Pengambean Pengulapan, Cacahan dan Segehan Panca Lima. Semua yang di persiapkan merupakan persembahan kepada Ida Sang Hyang Widhi Wasa dengan segala manifestasiNya. Karena apa yang kita lakukan merupakan bentuk pelayanan kepada Tuhan, begitu juga dalam pelaksanaan Upacara Ngerasakin melalui kitab suci Weda.

Pada aspek budaya dan seni (estetika), pelaksanaan Upacara Ngerasakin merupakan suatu kegiatan budaya, karena semua kegiatan prilaku yang dilakukan oleh manusia adalah budaya. Upacara Ngerasakin sebagai perilaku beragama Hindu lahir dari pemikiran manusia sebagai usaha untuk menyelamatkan hidupnya. Upacara Ngerasakin merupakan sebagai salah satu usaha manusia dalam menyelamatkan diri dari sifat buruk yang dialami pada proses perpindahan tingkat kehidupan menuju tingkatan hidup lainya. Menurut Van Gennep, manusia dari banyak kebudayaan selalu terdapat saat yang penting, yang mengikat hidupnya dari masa lalu ke masa yang akan dihadapinya. Kebutuhan pokok hidup manusia menurut ajaran agama Hindu adalah kebahagiaan lahir dan batin. Upacara Ngerasakin yang berfungsi sebagai penyucian lahir batin manusia yang bertujuan untuk kebahagian hidup manusia secara lahir dan batin. Di lihat dari bentuk upakara (banten) yang digunakan dalam pelaksanaan 


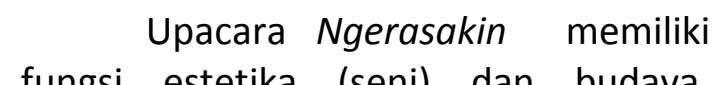
Disamping memiliki fungsi budaya, banten juga sebagai pengembangan seni dan estetis.

Dengan demikian dari uraian di atas, fungsi Upacara Ngerasakin yang dilakukan oleh masyarakat, baik dilihat dari proses pelaksanaanya dan juga upakara (banten) dan sarana lainya yang digunakan sebagai sebuah sistem yang terdiri dari sub -sub sistem lain sebagai pendukungnya.

Sebagaimana diungkapkan

dalam Teori Fungsionalisme Struktural yang menekankan pada tercapainya keseimbangan dan keharmonisan hidup sebagai individu dan kelompok (masyarakat). Manusia atau masyarakat adalah sebagai sesuatu sistem perimbangan dan keharmonisan. Sebagaimana dikatakan oleh Talchott Parsons, masyarakat merupakan sebagai suatu sistem perimbangan seperti halnya tubuh manusia yang terdiri dari berbagai bagian yang memiliki fungsi masingmasing yang mendukung sistem tubuh secara keseluruhan. Satu dengan bagian lainya mempunyai hubunga yang saling ketergantungan. Salah satu tidak berfungsi akan berpengaruh terhadap fungsi lainya. Demikian juga dalam masyarakat, setiap orang atau kelompok dapat memberikan sumbangansumbangan yang khas melalui peranannya masing-masing yang telah ditentukan demi lestarinnya sistem perimbangan secara keseluruhan. Upacara Ngerasakin sebagai sebuah sistem dapat berfungsi untuk memelihara eksetensi dan stabilitas masyarakat secara keseluruhan. Prilaku masyarakat agama dalam pelaksanaan Upacara Ngerasakin sebagai aktifitas masyarakat yang dapat mengarahkan keadaan masyarakat yang harmonis, stabil dan seimbang. Upacara Ngerasakin dapat mengharmoniskan struktur dalam diri manusia (jasmani dan rohani) sebagai mahluk individu dan dan mengharmoniskan struktur masyarakat sebagai mahluk sosial melalui prilaku hidupnya yang selalu menjunjung tinggi nilai-nilai kebenaran. Melalui dogmadogma dan mitos-mitos keagamaan yang tidak terikat oleh tempat dan waktu dapat mendorong dan menjadi dasar dari prilaku hidup keagamaan. Upacara Ngerasakin yang berfungsi sebagai bentuk pengabdian kepada Tuhan yang diyakini oleh seseorang dapat menghantarkan hidup manusia mencapai kebahagiaan lahir dan batin dan tercapainya tujuan hidup beragama. Atas dasar inilah yang mendorong manusia untuk melaksanakan upacara termasuk Upacara Ngerasakin . Berbagai jenis upakara (banten) dalam Upacara Ngerasakin , merupakan sub-sub sistem yang mendukung sebuah sistem pemujaan kepada Tuhan dalam bentuk Upacara Ngerasakin . Kalau salah satu sub sistem banten ini tidak berfungsi akan menjadi berpengaruh terhadap fungsi banten yang lainya dan berdampak pada kualitas nilai yang ada didalam pelaksanaan Upacara Ngerasakin.

$$
\text { Demikian halnya dengan }
$$
masyarakat pendukungnya, antara tukang banten (sarati), pimpinan upacara (Pandita/Pinandita) dan Sang Yajaman (Pelaksana Uapacara) adalah merupakan bagaian dari sub sistem dalam sistem Upacara Ngerasakin .

\section{Makna Upacara Ngerasakin}

Upacara Ngerasakin juga merupakan pelaksanaan Panca Maha Yadnya yaitu : Dewa Yadnya ini dapat kita 
lihat dalam persembahan kepada Ida Hyang Widhi Wasa sebagai rasa bhakti kepada Tuhan, yang diwujudkan dalam persembahan upakara (banten) kepada Tuhan dalam manifestasinya sebagai Surya (Siwaraditya).

Persembahan dengan Segehan merupakan perujudan rasa bakti dan hormat kepada para bhuta kala merupakan pelaksanaan Bhuta Yadnya. Secara religius Upacara Ngerasakin bermakna sebagai wujud rasa terima kasih kepada yang memiliki dan menjaga Abian (perkebunan) dan Carik (sawah) secara niskala yang merupakan manisfestasi Ida Sang Hyang Widhi Wasa dalam bentuk Jero Sedahan Abian dan Jero Sedahan Carik. Secara religius pelaksanaan Upacara Ngerasakin mengandung makna untuk menyerap nilai etis dan religius yang disimbolkan berbagai jenis banten yang digunakan dalam Upacara Ngerasakin.

Bentuk banten yang di gunakan dalam Upacara Ngerasakin yaitu Daksina sebagai simbol Ida Sang Hyang Widhi Wasa. Pada daksina misalnya terdapat kelapa, telor, pisang kayu, tingkih, beras, bija ratus rampak, dan peselan. Banten daksina menggambarkan badan alam makroskosmos, dalam mithologi bahwa kelapa itu tidak lain wujud makrokosmos atau alam jagad raga karena berasal dari kepala Dewa Brahma.

Telor sebagai jantung atau papusuh karena bentunknya menyerupai jantung, tingkih sebagai ungsilan, pangi simbolik sebagai hati karena bentuknya menyerupai hati dan warnanya. Pisang kayu sebagai tulang karena bentuknya seperti tulang. Bija ratus sebagai jeroan (usus). Kemudian tampak sebagai simbol cakra berputar yang melambangkan hukum alam selalu bergerak.
Peselan melambangkan Panca Dewata. Penyerapan nilai-nilai etis dan riligius ini bertujuan untuk membangun atau meningkatkan sifat-sifat ketuhananyang ada dalam diri manusia. Secara hakekat manusia bersumber pada Tuhan, memiliki sifat-sifat ketuhanan. Dengan demikian pelaksanaan Upacara Ngerasakin sebagai salah satu cara umat Hindu untuk membangun manusia seutuhnya. Nilai keseimbangan dan keharmonisan secara horizontal dan vertikal terefleksi dalam konsep Tri Hita Karana yakni keseimbangan secara horizontal dengan alam (Palemahan) dan sesama manusia (Pawongan), serta keseimbangan secara vertikal dengan Tuhan atau Ida Sang Hyang Widhi Wasa (Parhyangan). Konsep Tri Hita Karana mengajarkan kepada umat Hindu untuk menjaga keseimbangan dan hubungan yang harmonis dengan Tuhan Yang Maha Esa. Pelaksanaan Upacara Ngerasakin mengandung makna ungkapan rasa syukur ke hadapan Tuhan Yang Maha Esa melalui manifestasinya sebagai Jero Sedahan Abian atau Carik atas segala karunianya, berupa hasil bumi yang melimpah ruah. Sehingga dengan hasil bumi ini masyarakat bisa hidup tentram nyaman tanpa ada masalah.

\section{KESIMPULAN}

Dalam Masyarakat Hindu di Bali, telah lama menjaga keharmonisan hubungan antara manusia baik Tumpek Bubuh / Tumpek wariga di dalam hari besar ini terdapat suatu upacara yang lebih spesifik yaitu Upacara Ngerasakin merupakan pelaksanaan Panca Maha Yadnya yaitu : Dewa Yadnya ini dapat kita lihat dalam persembahan kepada Ida Hyang Widhi Wasa sebagai rasa bhakti kepada Tuhan, yang diwujudkan dalam persembahan upakara (banten) kepada 
Tuhan dalam manifestasinya sebagai Surya (Siwaraditya). Persembahan dengan Segehan merupakan perujudan rasa bakti dan hormat kepada para bhuta kala merupakan pelaksanaan Bhuta Yadnya. Secara religius Upacara Ngerasakin bermakna sebagai wujud rasa terima kasih kepada yang memiliki dan menjaga Abian (perkebunan) dan Carik (sawah) secara niskala yang merupakan manisfestasi Ida Sang Hyang Widhi Wasa dalam bentuk Jero Sedahan Abian dan Jero Sedahan Carik. Secara religius pelaksanaan Upacara Ngerasakin mengandung makna untuk menyerap nilai etis dan religius.

\section{DAFTAR PUSTAKA}

Adnyana I Nyoman Minder. 2012. Arti dan Fungsi Banten Sebagai Sarana Persembahyangan. Denpasar : Pustaka Bali Post

Ali Sayuti. 2002. Metodelogi Penelitian Agama Pendekatan Teori \& Praktek. Jakarta : Raja Grafindo Persada

Ananda I Nyoman. 2004.

Wraspatitattwa, Kajian Bentuk Fungsi dan Makna, Tesis Magister Brahma Widya, Program Pascasarjana Institut Hindu Dharma Negeri Denpasar

Bagus Lorens. 2005. Kamus Filsafat. (Cetakan Keempat). Jakarta : PT Gramedia Pustaka Utama Bandana I Gde Wayan Soken, Dkk. 2012. Bahasa, Aksara, dan Sastra Bali dalam Wacana Seremonial Kematian. Denpasar : Cakra Press.

Bogdan \& Taylor. 1992. Metode Penelitian Kualitatif Suatu Pendekatan Fenomenologis Terhadap Ilmu-Ilmu Sosial. Surabaya : Usaha Nasional.
Bugin Burhan. 2003. Analisis Data Penelitian Kualitatif. Jakarta : Raja Grafindo Persada

Bugin Burhan. 2001. Metodelogi Penelitian Sosial. Surabaya : Airlangga University Press

Campbell Tom. 2001. Tujuh Teori Sosial. Yogyakarta : Kanisius

Coulson J. 1978. Oxford Illustrated Dictiona. Oxford : Oxford University Press

Djaja Sudarman. 1999. Semantik Dua Pemahaman Ilmu Makna. Bandung : Rafika Aditama

Endraswara Suardi, 2003. Metodelogi Penelitian Kebudayaan. Yogyakarta : $\quad$ Gajah MadaUniversitas Press

Gie The Liang. 1996. Garis Besar Esatetika (Filsafat Keindahan) Yogyakarta : Karya

Gulo W. 2002. Metodelogi Penelitian, Cetakan Ketiga). Jakarta : PT GramediaWidiasarana Indonesia

Hadi Sutrisno. 2000. Metodelogi Researc. Yogyakarta : Andi

lqbal Hasan. 2002. Pokok-Pokok Penelitian dan Aplikasinya. Indonesia : Ghalia Kartono. 1986. Metodelogi Penelitian. Yogyakarta. Universitas Gajah Mada

Kleden Ignas. 1996. Pergeseran Nilai Moral Perkembangan Seni dan Perubahan Nilai Moral Dalam Kalam, No VIII. Jakarta : Pustaka Grafindo

Koenjaraningrat. 1987. Sejarah Teori Antropologi, Jakarta : Universitas Indonesia

Koenjaraningrat. 1996. Pengantar Antropologi. Jakarta : PT Bineka Cipta

Liputo Yuliani. 1995, Kamus Filsafat. Bandung : Remaja Rosdakarya 
Mikkelsen Britha. 1999. Metode Penelitian Partisipatoris dan Upaya-Upaya Pemberdayaan. Jakarta : Yayasan Obor Indonesia

Moleong Lexy J. 2001. Metodelogi Penelitian Kualitatif. Bandung : PT Remaja Rosda Karya Piliang Yasraf Amir. 2003. Hipersemiotik Tafsir Cultural Studies Atas Matinya Makna. Yogyakarta : Jalasutra.

Polama Margaret. 2003. Sosiologi Konteporer. Jakarta : Raja Grafindo Persada

Purwita Ida Bagus Putu. 1984. Desa Adat dan Banjar di Bali. Denpasar : Kawi Sastra

Raho Bernard. 2007. Teori Sosiologi Modern. Jakarta : Prestasi Pustakarya

Ritiaksa I Wayan. 2012. Upacara Nyentuk. Surabaya : Paramita

Strauss \& Corbin. 2003. Metode Penelitian Kualitatif. Yogyakarta : Pustaka Pelajar

Suprayogo. 2001. Metodelogi Penelitian Sosial-Agama. Bandung : PT Rosdakarya

Suarjaya I Wayan. 2010. Analisis Upacara Wana Kertih di Pura Batu Karu Desa Wongaya Gede. Surabaya : Paramita

Titib I Made. 2009. Teologi dan SimbolSimbol Dalam Agama Hindu. Surabaya : Paramita - 2003. Veda Sabda Suci (Pedoman Praktis Kehidupan). Surabaya : Paramita

Triguna Yudha Ida Bagus Gde. 2000. Teori Tentang Simbol. Denpasar: Widya Dharma Universitas Hindu Indonesia

Udayana I Dewa Gede Alit. 2009. Tumpek wariga Kearifan Lokal Bali Untuk
Pelestarian Sumber Daya Tumbuh-

Tumbuhan. Surabaya : Paramita

Wiana I Ketut. 2009. Suksmaning Banten. Surabaya : Paramita 2007. Tri Hita Karana

Menurut KonsepHindu. Surabaya : Paramita 